Suokas, Juho (2020). Testing Usability Methods in Translation Courses: Personas and Heuristic Evaluation. Current Trends in Translation Teaching and Learning E, 7, 4-38. 10.51287/cttl_e_2020_2_juho_suokas $</$ doi

\title{
TESTING USABILITY METHODS IN TRANSLATION COURSES: PERSONAS AND HEURISTIC EVALUATION
}

Juho Suokas

University of Eastern Finland

\section{Abstract}

To make translations better suited for specific target audiences, Suojanen et al. (2015) have suggested applying methods of usercentered translation (UCT). This study examines user-centered translation as part of university translation courses. The aim is to examine how translation students experience using two UCT methods: personas and heuristic evaluation. The students produced written comments during courses where the methods were applied. The student experience was examined by using the principles of qualitative content analysis. The analysis suggests that the methods have benefits for such matters as better understanding of the target audience and a more systematic process of evaluation. However, the methods also have drawbacks, such as the extra time and effort required. The specific heuristics were also found to be problematic to use. Usercentered translation has good potential for translator training, but the specific methods require refinement.

Keywords: user-centered translation, personas, heuristic evaluation, usability, translator training 
Suokas, Juho (2020). Testing Usability Methods in Translation Courses: Personas and Heuristic Evaluation. Current Trends in Translation Teaching and Learning E, 7, 4-38.10.51287/cttl_e_2020_2_juho_suokas </doi

\section{INTRODUCTION}

The target text reader is an integral part of any translation project. However, ways to address the reader have often been left to the translator's discretion. Similarly, in translator training, students are constantly reminded of the importance of considering the reader and the function of the text, but the actual ways of doing this can be vague. Since the translator might have a different idea of the reader than other actors involved in the process, such as the client ordering the translation, a systematic method of addressing the reader would benefit the process. Tytti Suojanen, Kaisa Koskinen, and Tiina Tuominen (2012, 2015) have presented the model of user-centered translation (UCT) to address this issue. The idea of UCT is to apply principles of usability research and user-centered design to the translation process.

This article reports the results of a study in which two UCT methods, personas and heuristic evaluation, were applied in translator training. The material was gathered from written feedback students produced after using the two methods. The aim of this study is to examine the student experience of applying the two user-centered translation methods in translation courses. Written data produced by the students was analysed using the principles of qualitative content analysis.

The article is divided into five parts. This introduction is followed by the theoretical framework, which discusses usercentered translation in more detail, and an introduction to the 
Suokas, Juho (2020). Testing Usability Methods in Translation Courses: Personas and Heuristic Evaluation. Current Trends in Translation Teaching and Learning E, 7, 4-38.10.51287/cttl_e_2020_2_juho_suokas</doi

two UCT methods used during the courses. Section three describes the research material, how the methods were applied in the courses, and how the data was analysed. Section four presents the findings of the analysis along with examples from the data. Section five concludes the paper.

\section{USER-CENTERED TRANSLATION}

The model of user-centered translation (UCT) was introduced into Translation Studies by Tytti Suojanen, Tiina Tuominen and Kaisa Koskinen $(2012,2015)$. The idea of UCT is to apply methods and practices from user-centered design to translation practice. User-centered translation focuses on how to consider the end-user and the use situation during the translation process. The UCT model has shown potential in practice (e.g. Suokas et al. 2015), and its methods have been used in a number of master's theses (e.g. Otava 2013, Suominen 2018). Since UCT has a strong focus on the purpose of translations, it can be seen as a practically-oriented continuation of the functionalist approach to translation (see e.g. Nord 2013).

The focus of UCT is on the translation's usability and the user experience. Usability is described by Suojanen et al. (2015: 13) as: "the ease of use of a product in a specified context of use" and user experience is described as: "a holistic concept, which includes all the user's emotions, beliefs, preferences, perceptions, physical and psychological responses, behaviors and accomplishments". Usability is thus subjective to the user (or user group) and dependent on the context of use. For 
Suokas, Juho (2020). Testing Usability Methods in Translation Courses: Personas and Heuristic Evaluation. Current Trends in Translation Teaching and Learning E, 7, 4-38.10.51287/cttl_e_2020_2_juho_suokas</doi

instance, a person might prefer to drive a sports car over a van, but if the purpose is to help a friend move their belongings to a new house, the van would far exceed the sports car in terms of usability. The focus is similar in terms of the usability of texts. For example, eloquent and poetic expression might be desirable in some cases, but not so much on an airport restroom notice telling people not to put paper towels in the toilet. Jody Byrne defines the usability of texts as: "the extent to which readers can read a text, understand its content and perform whatever task is required by the text quickly and accurately and the extent to which they find the experience difficult or easy." (Byrne 2012: 201.) While not every text requires the reader to perform tasks, as in Byrne's definition, I nevertheless argue that usability is an attribute that can be found and evaluated in any type of text.

The user-centered design process is an iterative one in which the data gathered from the users is applied in different stages of the process with the objective of a user-centered end product. (Suojanen et al. 2015: 3-4.) In translation, this can include gathering data on the readers of a translation before translating the text, using the data to tailor the translation choices to meet the readers' needs, and perhaps testing the translation with some members of the target audience.

Naturally, not every translation project would benefit from multiple additional stages that analyse how well it meets the needs of its readers. Suojanen et al. (2012, 2015) suggest different methods from usability research and user-centered design for different translation purposes. These methods range 
Suokas, Juho (2020). Testing Usability Methods in Translation Courses: Personas and Heuristic Evaluation. Current Trends in Translation Teaching and Learning E, 7, 4-38.10.51287/cttl_e_2020_2_juho_suokas</doi

from simple mental models, such as implied readers and user personas, to full-scale empirical methods, such as usability testing and ethnographic fieldwork. A full-scale user test might not benefit the process as a whole in small translation projects and projects where time is limited, however, such a test could be beneficial in large, more prestigious projects. Consequently, different projects benefit from different methods. For this study, I chose two methods that appear to be relatively simple to apply to most translation projects since they do not require as much in terms of additional resources or extra work to implement into practice. These methods are personas and heuristic evaluation, which I will introduce briefly in sections 2.1 and 2.2.

\subsection{Personas}

Personas are a commonly used method in user-centered design. These are fictional characters created to represent the users of a product or service, in this case, the readers of a translation. Personas are most often based on empirical data gathered beforehand from the intended target audience. This data is used to classify the audience into different user groups based on their characteristics and interests. Individual personas are then created to represent these groups. However, for smaller translation projects, the translator can create the personas based on other factors, such as professional intuition and experience or textual analysis, for instance, examining the type of 'implied reader' portrayed in the text (Suojanen et al. 2015: 62-66).

More than one persona is often created for a design process to 
Suokas, Juho (2020). Testing Usability Methods in Translation Courses: Personas and Heuristic Evaluation. Current Trends in Translation Teaching and Learning E, 7, 4-38.10.51287/cttl_e_2020_2_juho_suokas</doi

obtain a detailed picture of the end user. A persona is given a name, some background information, personality traits, and information on how and why they use the product or service in question. This is done in order to create a concrete image of the reader. The strategies and decisions involved in the translation process can then be examined from the persona's perspective. The translator can consider questions such as 'is this persona used to reading texts written in this manner', or 'would they understand this terminology'? Personas can also help create mutual understanding about the purpose and audience of the text among different actors in the translation process, for instance, in a project including multiple translators, proof-readers, and client representatives. (Suojanen et al. 2015: 70-71.)

\subsection{Heuristic evaluation}

The usability of a product is analysed systematically in heuristic evaluation, and the evaluation is based on a set of usability principles called heuristics. The heuristics themselves are most commonly listed according to themes, or topics, that include statements or questions related to the different points of focus. For instance, the heuristics could be made into a checklist against which the evaluator compares the evaluated product. Compared to other methods of evaluating usability, where users are a part of the process, heuristic evaluation is a more prescriptive method, where the evaluation is done by experts based on predetermined rules and principles. This is similar to many translation quality assessment models, where assessment is based on existing quality criteria. In addition, since heuristic 
Suokas, Juho (2020). Testing Usability Methods in Translation Courses: Personas and Heuristic Evaluation. Current Trends in Translation Teaching and Learning E, 7, 4-38.10.51287/cttl_e_2020_2_juho_suokas $</$ doi

evaluation does not include actual users, it is a more costefficient method of evaluating usability than those that involve actual users. In usability research, the expert evaluators are experts of usability, the product, or both. In translation, these experts can be professional translators or professionals on the topic of the text.

When a heuristic evaluation is performed, the evaluator goes through the product, looking for any parts that violate the chosen heuristics. When problems are identified, the evaluator marks them, assigns an appropriate heuristic that the problem violates, gives it a severity rating, and offers a possible solution. Heuristics can also be used outside the evaluation process as a guideline for decision making during the design process. The various quality guidelines and assessment practices used in the translation industry also share a resemblance to heuristics.

There are various heuristics, especially for user interface design, but not that many text-specific ones. I chose the general usercentered translation heuristics presented in the book Usercentered Translation by Suojanen, Koskinen, and Tuominen (2015: 90). The ten heuristics and the details of the evaluation will be presented in more detail in section 3.2. These heuristics were tested in practice in a previous study by Suojanen and Tuominen (2015), which will be discussed in section 4.4. 
Suokas, Juho (2020). Testing Usability Methods in Translation Courses: Personas and Heuristic Evaluation. Current Trends in Translation Teaching and Learning E, 7, 4-38.10.51287/cttl_e_2020_2_juho_suokas $</$ doi

\section{MATERIAL AND METHOD OF ANALYSIS}

\subsection{Material}

The material for this study was gathered from university courses where user-centered translation was applied. The three courses selected included two courses held at the University of Eastern Finland (UEF): Special Field Translation Finnish-English 2015 (SFT 1 2015) and Special Field Translation Finnish-English 2016 (SFT 1 2016); and one course held at the University of Turku (UTU), Multilingual Translation Workshop 22015 (MTW 2 2015).

During all three courses, the two usability methods - personas and heuristic evaluation - were first presented to the students during a UCT presentation session and later applied independently to the students' own course work. The two methods were applied during the UCT presentation sessions by using the webpage of a large European music store as the practice material. The students first worked in small groups to familiarise themselves with the webpage and then created personas to represent its intended users. Once the personas were done, a discussion was held, in which the students presented their personas to the rest of the class. After the discussion on the personas, the students chose a selected part of the site to analyse using heuristic evaluation (described in more detail in section 3.2). The results of the evaluation were then shared and discussed with the rest of the class. The exact way the methods were used later in the students' own coursework varied among 
Suokas, Juho (2020). Testing Usability Methods in Translation Courses: Personas and Heuristic Evaluation. Current Trends in Translation Teaching and Learning E, 7, 4-38.10.51287/cttl_e_2020_2_juho_suokas $</$ doi

the three courses. These differences are presented in section 3.1.

The data consisted of the written feedback the students produced during the courses after using the methods. The students were informed of the purpose of the study early during the courses and were later asked to sign an informed consent form if they were willing to participate. While the assignments were required work for completing the courses, only the material of those students who signed the consent form were included in the data. The names of the students were redacted from the data and are represented as a code consisting of the course abbreviation and a two-digit number, for instance, SFT1610.

The analysis included 62 text documents, divided as follows: SFT15: 29, SFT16: 19, and MTW15: 14. The comments were mainly in Finnish. I translated all examples presented in this article from Finnish, otherwise they are presented in the original English where specified. The data was analysed in the language in which it was originally produced, the translations were done after the analysis for the purpose of reporting the findings in this article. The aim of my translations was to retain the information content and some aspects of the individual styles of the students' writing. I will present the courses in more detail below. 
Suokas, Juho (2020). Testing Usability Methods in Translation Courses: Personas and Heuristic Evaluation. Current Trends in Translation Teaching and Learning E, 7, 4-38.10.51287/cttl_e_2020_2_juho_suokas $</$ doi

\subsubsection{Special field translation 1 FI-EN 2015 (SFT15)}

This BA-level course was held in 2015 at UEF. It targeted second- to third-year students, who already had some experience of translating texts both into Finnish and English - their L1 and L2, respectively. The course focused on texts from various special fields. The language pair was Finnish to English. Due to the large number of students (29), the course was divided into two groups. I taught both groups.

One lesson was designed to introduce the principles of UCT to the students and to get the students to practice using personas and heuristics. The students were then asked to use the two methods in the course assignments that followed the workshop. A persona was created for their next translation assignment, which was a text on subtitling conventions. The students used heuristic evaluation to evaluate and give feedback on each others' translations. The students were able to select the translation to give to their partner for analysis. This was also part of the final assignment of the course, which was to compile a portfolio of selected translations that had been revised according to the feedback received throughout the course from both instructor and peers.

\subsubsection{Special field translation 1 FI-EN 2016 (SFT16)}

This BA-level course was similar to the previous one and was held from September to December, 2016. The course was also divided into two groups. While I taught the previous course, the 
Suokas, Juho (2020). Testing Usability Methods in Translation Courses: Personas and Heuristic Evaluation. Current Trends in Translation Teaching and Learning E, 7, 4-38.10.51287/cttl_e_2020_2_juho_suokas</doi

majority of this course was taught by another instructor. I held two workshops similar to those described in section 3.1. The methods were used in a similar manner, but the personas were created for a text that described an oatmeal product. Similar to the previous SFT course, the students chose a translation to give to a peer for heuristic evaluation.

\subsubsection{Multilingual Translation Workshop 22015 (MTW15)}

The Multilingual Translation Workshops (MTWs) are MA-level translation project courses held at the University of Turku. The MTWs target fourth- and fifth-year students, who are close to completing their studies. The idea is that students of translation from different languages work in multilingual teams as a simulated translation company. The MTW courses are held in cooperation with local language service providers. The course has received accolades from the university for its approximation to work life.

This course was held at UTU from September to December, 2015. One session included a workshop similar to the one above, where I presented the personas and heuristics, and the students practiced using the methods. The methods were then applied in the coursework: the groups created personas for two of their translation projects before beginning the translation work. Each team performed external reviews of other teams' translations by applying heuristic evaluation. The results of these evaluations were shared among the teams. As opposed to the courses described in sections 3.1.1 and 3.1.2, the participants were MA- 
Suokas, Juho (2020). Testing Usability Methods in Translation Courses: Personas and Heuristic Evaluation. Current Trends in Translation Teaching and Learning E, 7, 4-38.10.51287/cttl_e_2020_2_juho_suokas $</$ doi

level students close to the end of their studies. Instead of working individually on translation projects, the students worked in multilingual teams with the same source texts but with different target languages, according to their studies.

\subsection{How the heuristic evaluation was carried out}

As stated in section 2.2, the heuristics used in this study were the general UCT heuristics suggested by Suojanen et al (2015). The ten heuristics are presented in Table 1.

Table 1. Usability heuristics for user-centered translation (Suojanen et al. 2015: 90)

\begin{tabular}{|c|c|}
\hline $\begin{array}{l}\text { 1. Match between translation } \\
\text { and specification }\end{array}$ & $\begin{array}{l}\text { Why is the translation needed and } \\
\text { does it fulfil the requirements } \\
\text { defined in the specification? }\end{array}$ \\
\hline $\begin{array}{l}\text { 2. Match between translation } \\
\text { and users }\end{array}$ & $\begin{array}{l}\text { Who are the users of the translation } \\
\text { and how do their characteristics } \\
\text { affect translation solutions? } \\
\text { Are there possibilities for supporting } \\
\text { different kinds of users? } \\
\text { Do the textual choices reflect the } \\
\text { information needs of the users? }\end{array}$ \\
\hline $\begin{array}{l}\text { 3. Match between translation } \\
\text { and real world }\end{array}$ & $\begin{array}{l}\text { Is the translation aligned with its } \\
\text { cultural context? } \\
\text { Is cultural adaptation required? }\end{array}$ \\
\hline $\begin{array}{l}\text { 4. Match between translation } \\
\text { and genre }\end{array}$ & $\begin{array}{l}\text { Does the translation match the } \\
\text { conventions of the genre in } \\
\text { question? } \\
\text { Are the visual, auditory and other } \\
\text { multimodal elements appropriate for } \\
\text { the new context? }\end{array}$ \\
\hline
\end{tabular}


Suokas, Juho (2020). Testing Usability Methods in Translation Courses: Personas and Heuristic Evaluation. Current Trends in Translation Teaching and Learning E, 7, 4-38.10.51287/cttl_e_2020_2_juho_suokas</doi

\begin{tabular}{|c|c|}
\hline 5. Consistency & $\begin{array}{l}\text { Is the translation consistent in terms } \\
\text { of style, terminology, phraseology } \\
\text { and register? }\end{array}$ \\
\hline 6. Legibility and readability & $\begin{array}{l}\text { Do the visual elements of the } \\
\text { translation correspond to the } \\
\text { reader's physiological capabilities } \\
\text { and relevant cultural guidelines? } \\
\text { Is the user guided through the } \\
\text { translation by using appropriate } \\
\text { signposting for the genre in } \\
\text { question? } \\
\text { Are the user's efforts of } \\
\text { interpretation sufficiently } \\
\text { minimized? }\end{array}$ \\
\hline 7. Cognitive load and efficiency & $\begin{array}{l}\text { Is the translation well crafted } \\
\text { enough to be easy to memorize and } \\
\text { learnable - that is, clear and } \\
\text { comprehensible? } \\
\text { Do the users need guidance for } \\
\text { using the translation and, if so, in } \\
\text { which format? }\end{array}$ \\
\hline 8. Satisfaction & $\begin{array}{l}\text { Does the translation produce a } \\
\text { pleasurable and/or rewarding user } \\
\text { experience? }\end{array}$ \\
\hline $\begin{array}{l}\text { 9. Match between source and } \\
\text { target texts }\end{array}$ & $\begin{array}{l}\text { Has all relevant source material } \\
\text { been translated? } \\
\text { Is there unwanted linguistic or } \\
\text { structural interference? }\end{array}$ \\
\hline 10. Error prevention & $\begin{array}{l}\text { Have the potential risks of } \\
\text { misunderstanding been minimized? }\end{array}$ \\
\hline
\end{tabular}


Suokas, Juho (2020). Testing Usability Methods in Translation Courses: Personas and Heuristic Evaluation. Current Trends in Translation Teaching and Learning E, 7, 4-38.10.51287/cttl_e_2020_2_juho_suokas </doi

Heuristic evaluation often includes a severity rating alongside the classification of errors. Nielsen's (1994) 0-4 severity rating was applied in this study:

$0=\mathrm{I}$ don't agree that this is a usability problem at all

$1=$ Cosmetic problem only: need not be fixed unless extra time is available on project

$2=$ Minor usability problem: fixing this should be given low priority

3 = Major usability problem: important to fix, so should be given high priority

4 = Usability catastrophe: imperative to fix this before product can be released

Following the principles of heuristic evaluation, the students went through the evaluated text and put problems they found in a table, described which heuristic the problem violated, gave a severity rating, and suggested a fix where possible. A fictional example is presented in Table 2.

Table 2. Fictional example of heuristic evaluation

\begin{tabular}{|c|c|c|c|c|c|}
\hline $\begin{array}{c}\text { Evalua- } \\
\text { tor }\end{array}$ & $\begin{array}{c}\text { Loca- } \\
\text { tion }\end{array}$ & Problem & Heuristic & $\begin{array}{c}\text { Sever- } \\
\text { ity }\end{array}$ & Suggestion \\
\hline AB & $\begin{array}{c}\text { Chap- } \\
\text { ter 2 } \\
\text { Pages } \\
42-45\end{array}$ & $\begin{array}{c}\text { Terms 'inter- } \\
\text { lingual com- } \\
\text { munications } \\
\text { expert' and } \\
\text { 'translator' } \\
\text { are used inter- } \\
\text { changeably. }\end{array}$ & $\begin{array}{c}\text { 5. Con- } \\
\text { sistency }\end{array}$ & 2 & $\begin{array}{c}\text { Use only } \\
\text { one term } \\
\text { ('transla- } \\
\text { tor'). }\end{array}$ \\
\hline
\end{tabular}


Suokas, Juho (2020). Testing Usability Methods in Translation Courses: Personas and Heuristic Evaluation. Current Trends in Translation Teaching and Learning E, 7, 4-38.10.51287/cttl_e_2020_2_juho_suokas</doi

\subsection{Method of data analysis}

Qualitative content analysis (QCA) was used to analyse the data. In QCA, the parts of the data that are relevant to the research question are marked and given a description called a 'code'. The codes can be predetermined (deductive) or they can arise from the data (inductive). Often the coding is done in more than one stage, the initial coding is refined in subsequent stages, for example, by grouping codes together to create larger and more abstract categories and hierarchies. (Saldanha \& O'Brien 2013: 188-194.)

In this study, a deductive approach was chosen to focus the analysis on answering the research question 'how students have experienced applying the two user-centered translation methods in translation courses'. The coding was conducted by using a set of categories predetermined by the researcher prior to the analysis. These categories were used to identify student experience of working with personas, heuristics, and UCT in general. Parts of the data were also coded for other purposes, such as for improving the exercise and teaching in future courses, but these parts were not relevant to the study.

First, the following overarching groups of codes were created: general, persona, and heuristics. The 'general' code group consisted of all general comments the students made on UCT. The 'persona' code group consisted of comments specifically related to personas, and similarly the 'heuristics' code group consisted of comments specifically related to heuristics. The 
Suokas, Juho (2020). Testing Usability Methods in Translation Courses: Personas and Heuristic Evaluation. Current Trends in Translation Teaching and Learning E, 7, 4-38.10.51287/cttl_e_2020_2_juho_suokas $</$ doi

code groups were assigned the following three subcategories: positive, negative, and neutral. The subcategories were used to determine whether a comment 1) was a positive one, 2) pointed out problems or negative experiences the students had in using the methods, or 3) was neutral or ambivalent, or a suggestion for how to refine or develop the method. The codes used in the analysis are presented in Table 2, and examples are presented in section 4. 
Suokas, Juho (2020). Testing Usability Methods in Translation Courses: Personas and Heuristic Evaluation. Current Trends in Translation Teaching and Learning E, 7, 4-38.10.51287/cttl_e_2020_2_juho_suokas</doi

Table 2. Categories and subcategories of codes

\begin{tabular}{|c|c|c|c|}
\hline $\begin{array}{l}\text { Code } \\
\text { group }\end{array}$ & Subcategory & Description & Abbreviation \\
\hline \multirow{3}{*}{ General } & positive & $\begin{array}{c}\text { positive experiences with user- } \\
\text { centred translation in general }\end{array}$ & $\mathrm{G}+$ \\
\hline & negative & $\begin{array}{c}\text { problems and negative } \\
\text { experiences with user-centred } \\
\text { translation in general }\end{array}$ & G- \\
\hline & neutral & $\begin{array}{c}\text { neutral or ambivalent } \\
\text { comments (including } \\
\text { suggestions for development) } \\
\text { on user-centred translation in } \\
\text { general } \\
\end{array}$ & G / \\
\hline \multirow{3}{*}{ Persona } & positive & $\begin{array}{l}\text { positive experiences with } \\
\text { personas }\end{array}$ & $\mathrm{P}+$ \\
\hline & negative & $\begin{array}{c}\text { problems and negative } \\
\text { experiences with personas }\end{array}$ & P- \\
\hline & neutral & $\begin{array}{c}\text { neutral or ambivalent } \\
\text { comments (including } \\
\text { suggestions for development) } \\
\text { specifically on personas }\end{array}$ & $\mathrm{P} /$ \\
\hline \multirow{3}{*}{ Heuristics } & positive & $\begin{array}{c}\text { positive experiences with } \\
\text { heuristics }\end{array}$ & $\mathrm{H}+$ \\
\hline & negative & $\begin{array}{c}\text { problems and negative } \\
\text { experiences with heuristics }\end{array}$ & $\mathrm{H}-$ \\
\hline & neutral & $\begin{array}{l}\text { neutral or ambivalent } \\
\text { comments (including } \\
\text { suggestions for development) } \\
\text { specifically on heuristics }\end{array}$ & $\mathrm{H} /$ \\
\hline
\end{tabular}


Suokas, Juho (2020). Testing Usability Methods in Translation Courses: Personas and Heuristic Evaluation. Current Trends in Translation Teaching and Learning E, 7, 4-38.10.51287/cttl_e_2020_2_juho_suokas $</$ doi

\section{FINDINGS}

The findings of the data analysis are presented in this section. Qualitative analysis was conducted, but the number of the codes are presented to give context and a general idea of the data as a whole.

\subsection{General}

Focusing on translation usability was an overall positive experience for many students. This approach gave new perspectives on a translation and a practical background against which to examine it. Table 3 shows that most of the comments coded as 'general' were positive $(n=43)$ and a minority were negative $(n=7)$. There were as many positive comments as neutral or ambivalent ones, which included ideas for development or future use $(n=43)$.

Table 3 Number of overall general codes

\begin{tabular}{|c|c|c|}
\hline Category & Code & Count \\
\hline \multirow{4}{*}{ General } & G+ & 43 \\
\cline { 2 - 3 } & G- & 7 \\
\cline { 2 - 3 } & G / & 43 \\
\hline
\end{tabular}

The positive comments showed that many students had found it beneficial to apply a user-centered approach. Some students had discovered a new way of thinking about translation work (1). Many found that the focus on usability suited their translation process well $(2 \& 3)$. 
Suokas, Juho (2020). Testing Usability Methods in Translation Courses: Personas and Heuristic Evaluation. Current Trends in Translation Teaching and Learning E, 7, 4-38.10.51287/cttl_e_2020_2_juho_suokas</doi

(1) In theory, user-centered translation seemed like a good idea, and I felt how my thinking moved into a new kind of box. (SFT1513)

(2) Evaluating usability from different perspectives seemed to suit the translation process well and makes it easier to make translation choices from time to time. (SFT1525)

(3) Focusing on usability felt natural. I believe translation should be user-driven anyway, i.e. to think who is the primary reader of the translation and keep them in mind when translating. (MTW1501)

Only seven general comments were marked as negative. They were more focused on practical problems and the respondent's unfamiliarity with the idea of usability. For instance, comment 4 points out that it would be unfeasible for a freelance translator to actually gather data from the users. Similarly, some students were so used to their own translation processes that applying new approaches proved to be difficult.

(4) User-centered translation seemed complicated. Gathering data from the users and their wishes and needs? During the translation process? Somehow, that probably doesn't fit into the work of a freelance translator. (SFT1506)

(5) Focusing on usability felt strange, especially at first. I think I could not get the most out of the methods, or use them properly. I was too stuck with the more imprecise methods I am familiar with. (SFT1616)

There were notably more general comments marked neural 
Suokas, Juho (2020). Testing Usability Methods in Translation Courses: Personas and Heuristic Evaluation. Current Trends in Translation Teaching and Learning E, 7, 4-38.10.51287/cttl_e_2020_2_juho_suokas $</$ doi

$(n=43)$ than negative ones. Some of these neutral comments were more related to the individual methods, which are discussed in more detail in sections 4.2 and 4.3. Many of the neutral comments questioned whether or not the methods and a user-centered approach would be suitable for different situations (6).

(6) I think this user-perspective could be taken into more consideration in quality management, but it would be quite difficult in an EU text because the point of EU texts is to have different language versions closely resembling each other and similar to the style of previous similar texts. But, usercenteredness is essential when translating, say, websites, so these methods could well be used there. (MTW1512)

(7) I don't know how common this practice [of gathering data from the users] is, but I would not mind it, as long as I'm not the translator who is also responsible for gathering user feedback! (SFT1506)

An interesting point was that, when focusing on usability, some felt they were able to take more liberties and be less faithful to the source text.

(8) Anyway, evaluating usability felt more beneficial than focusing solely on the source text. I felt I could take more liberties in translating, especially in relation to usability. At the same time, however, I altered the style, form, and structure of the text, so I would not necessarily call my text a 'translation.' Maybe a compiled translation? (SFT1513)

The comments suggest that the students were mostly positive and open to the concept of UCT in general. Sections 4.2 and 4.3 
Suokas, Juho (2020). Testing Usability Methods in Translation Courses: Personas and Heuristic Evaluation. Current Trends in Translation Teaching and Learning E, 7, 4-38.10.51287/cttl_e_2020_2_juho_suokas</doi

present comments on the two methods.

\subsection{Personas}

Personas seemed to be well-received among the students. The number of positive comments was high $(n=52)$, but there were many negative $(n=36)$ and neutral comments $(n=49)$.

Table 4 Number of persona codes

\begin{tabular}{|c|c|c|}
\hline Category & Code & Count \\
\hline \multirow{3}{*}{ Persona } & $\mathrm{P}+$ & 52 \\
\cline { 2 - 3 } & $\mathrm{P}-$ & 36 \\
\cline { 2 - 3 } & $\mathrm{P} /$ & 49 \\
\hline
\end{tabular}

Personas were a simple and fun way of thinking about the target audience for many students. They found that personas gave them a more concrete grasp of the readers.

(9) I found creating personas an especially good exercise, because it is too rarely that I really think about what kind of a person will read the translated text. Of course, the user is always present in some way, but not as clearly as when doing these translations and evaluations. (MTW1512)

(10) Before, I have justified my translation choices along the lines of 'if the translation is read by some mechanic...' Now, the personas we created were more multidimensional than just 'some mechanic', they had more knowledge and a life beyond just the title of their occupation. (MTW1509)

(11) When applying personas, I felt that I could grasp the target 
Suokas, Juho (2020). Testing Usability Methods in Translation Courses: Personas and Heuristic Evaluation. Current Trends in Translation Teaching and Learning E, 7, 4-38.10.51287/cttl_e_2020_2_juho_suokas</doi

audience properly. Creating a specific scenario helped me understand the requirements of the text and gave me more motivation for translating when there was an example of someone who would read it too. (SFT1603)

Applying a persona was also seen to give a focus that would justify specific translation strategies $(12 \& 13)$. Some students found that by using a persona, they were able to consider the target audience much better than they had before (14 \& 15).

(12) The persona seemed useful. It did take some time to construct, but I felt that the end result was very useful when solving specific translation problems: would the persona understand the chosen terminology, style of translation, necessary additions, and possible omissions? (SFT1618)

(13) The persona gives the reviewer a new way of looking at the subject matter and makes it easier to define which parts of the translation are well suited for the reader and which would be unnecessary or too vaguely explained for the average customer. (SFT1604 original EN)

(14) Translating felt different and even easier when I had a clear picture of who I was translating for. (SFT1606)

(15) After creating the persona, I noticed that it was easier to make the translation more personal. Singling out just one, even an imagined, person from the mass, which the translator knows as the 'target audience' helps make the translating somehow more humane. [...] Although the persona was, at least in my case, a very exaggerated and unusual specimen, it did help in the translation process. (SFT 1607) 
Suokas, Juho (2020). Testing Usability Methods in Translation Courses: Personas and Heuristic Evaluation. Current Trends in Translation Teaching and Learning E, 7, 4-38.10.51287/cttl_e_2020_2_juho_suokas</doi

However, some students had problems considering the persona. There were different reasons for this. For instance, one student commented that their persona was too bland and uninspiring (16). However, others commented that their personas might have become too colourful and interesting, which could be either a benefit or a hindrance (18). One student did not like the general idea and considered it implausible to imagine what someone, who is very different from the translator, would think. (19)

(16) In many parts, I almost forgot that I had to consider the persona. The persona I created was probably somehow boring and bland, so that it did not feel important to consider. (MTW1501)

(17) At first, using the persona felt difficult, regardless that in our studies, the importance of considering the recipient of the text is always emphasised. (MTW1506)

(18) Similarly, coming up with a persona might even disturb thinking about the target audience, as probably happened on my part. I was so caught up in creating an over-stereotypical super hipster that I might have forgotten about other target audiences. Regardless, this probably did not affect the quality of the translation, at least not negatively. (SFT1607)

(19) I would think that the creation of a persona is a vain attempt to evade the need for a beta reader. One person's imagination cannot reach the same level as another set of brains. Another person's life experiences, different attitudes, skills, or knowledge base cannot just be imagined as one's own. (SFT 1512) 
Suokas, Juho (2020). Testing Usability Methods in Translation Courses: Personas and Heuristic Evaluation. Current Trends in Translation Teaching and Learning E, 7, 4-38.10.51287/cttl_e_2020_2_juho_suokas </doi

The personas were seen mostly as a fun and positive experience (20). Some students found them more helpful than others, while some questioned whether their use was beneficial or just time away from actual work (21).

(20) Creating the personas was fun, the story began to live imaginatively, and a whole life's story could have been written for the persona. (MTW1507)

(21) Creating a persona, however, requires extra time that no-one (?) will pay for, and the persona is a more limited concept than the diversity of the target audience. (SFT1512)

\subsection{Heuristic evaluation}

The heuristic evaluation was clearly the more troublesome of the two methods for most students. This can be seen from the number of negative comments $(n=79)$. The largest number of the comments were coded as neutral $(n=89)$, which also included many suggestions for developing the heuristics and the evaluation process. However, there were positive comments, too $(n=46)$, and some students had really enjoyed heuristic evaluation.

Table 5 Number of heuristics codes

\begin{tabular}{|c|c|c|}
\hline Category & Code & Count \\
\hline \multirow{3}{*}{ Heuristics } & $\mathrm{H}+$ & 46 \\
\cline { 2 - 3 } & $\mathrm{H}-$ & 79 \\
\cline { 2 - 3 } & $\mathrm{H} /$ & 89 \\
\hline
\end{tabular}


Suokas, Juho (2020). Testing Usability Methods in Translation Courses: Personas and Heuristic Evaluation. Current Trends in Translation Teaching and Learning E, 7, 4-38.10.51287/cttl_e_2020_2_juho_suokas</doi

A benefit of heuristic evaluation that many students commented on was that it made translation evaluation more systematic and thorough $(22,23)$. It was also seen to give new perspectives on translating (24).

(22) Evaluating usability was interesting, mainly because the translation could be evaluated systematically and because the problems in the text could be concretely identified. (SFT1501)

(23) The UCT table was a good help in my opinion, for it makes you divide the translation into smaller parts and analyse it based on different points; it goes to the so-called grass-roots level, to see what is possibly amiss or what is good in the translation. For these are matters you don't really pay attention to and become blind to in your own translations. (SFT1509)

(24) Using the heuristics felt surprisingly nice [...] By evaluating another's translation from the perspective of the heuristics, I too understood new areas to consider while translating, which sometimes become forgotten. (MTW1505)

There were differences between the students' personal preferences. Some students enjoyed the specific points of focus that heuristics provided ( $25 \& 26)$, while others found them irritating and limiting ( $27 \& 28)$. Potential was also seen in the heuristics as an addition to an existing CAT tool (29).

(25) Giving feedback through heuristic evaluation was enjoyable since it gives a concrete framework for feedback. (SFT1503)

(26) I found it very pleasing to carry out the heuristic evaluation. 
Suokas, Juho (2020). Testing Usability Methods in Translation Courses: Personas and Heuristic Evaluation. Current Trends in Translation Teaching and Learning E, 7, 4-38.10.51287/cttl_e_2020_2_juho_suokas $</$ doi

Although, with my text, I could not make the most out of the technique, but I found it easily approachable and a clear way to address problems in the text. (SFT1603)

(27) To be honest, I do not like doing heuristic evaluation, because I can evaluate readability and other factors without the heuristics, and I feel that the heuristics rather limited my thinking. (MTW1503)

(28) The heuristics gave the impression that they were definitely invented by some engineer. The information could be easily compiled and organised, but sometimes it would definitely be easier to just say what's wrong. (SFT1510)

(29) If the heuristics could be used together with some translation memory or text editor, it would be much more efficient. You could just pick a category from the list and use a template to describe the problem. (SFT1613)

The severity ratings used in the evaluation (as presented in section 3.2) were also seen to be a welcome addition that could help evaluate translations in the future.

(30) What was new in the exercise were the severity ratings of the problems. I don't feel that our translating studies have focused on the nature of severity, so that would be useful to learn. I might consider applying it in future evaluations of others' as well as my own translations. (SFT1602)

(31) On the other hand, it was nice to be able to give quite harsh critique of a specific subject and then sort of nullify the critique by giving it a low severity rating. (SFT1503)

Perhaps the most noticeable problems with the heuristics were 
Suokas, Juho (2020). Testing Usability Methods in Translation Courses: Personas and Heuristic Evaluation. Current Trends in Translation Teaching and Learning E, 7, 4-38.10.51287/cttl_e_2020_2_juho_suokas $</$ doi

that the specific heuristics used in the evaluation needed refinement. The students found overlapping between the different categories and had trouble identifying under which heuristic a specific problem could be categorised.

(32) I noticed overlapping in some of the heuristics, in many places, I would combine readability and satisfaction with each other. Others commented too that [the problems] could fit under multiple heuristics. (MTW1507)

(33) Some heuristics seemed to overlap or be consequential to each other. For instance, the 'cognitive load and efficiency' and 'error prevention' heuristics seemed to suggest the same thing: the reader's understanding. (SFT1519)

(34) Even the descriptions of the heuristics were such that it was difficult to match them with certain problems, such as missing articles or strange sounding word choices [...] some mistakes were difficult to categorise, because the definitions were too abstract. (SFT1617)

(35) My first experience with heuristic evaluation was confusing, to say the least, since dividing the problems into different categories felt somewhat random. (SFT1524)

An interesting concern was how to use heuristics to define problems that are apparently caused by the source text, such as factual errors, textual ambiguity, or poor source language quality.

(36) Sometimes the text had actual factual errors, which could not be paired with a heuristic, for they were not necessarily 
Suokas, Juho (2020). Testing Usability Methods in Translation Courses: Personas and Heuristic Evaluation. Current Trends in Translation Teaching and Learning E, 7, 4-38.10.51287/cttl_e_2020_2_juho_suokas $</$ doi

interference related to heuristic 9 (match between source and target texts). (MTW1514)

Some students were unhappy that the heuristics focused on identifying mistakes; they would have preferred to give positive feedback, too (37). This was recognised during the SFT courses, where the students were told they could also refer to heuristics to point out well done parts (38). The focus on mistakes was considered an issue when evaluating texts that did not have many problems (39\& 40).

(37) It would be nice to be able to say something positive about the evaluated translation, but the heuristics were only concerned with errors. (MTW1503)

(38) My major critique of the heuristics is that they are basically used just to give negative feedback, to point out what mistakes the translator has made. However, we were given the chance to use the heuristics to give positive feedback, too. Why can't this always be the case? (SFT1514)

(39) I found that the heuristic evaluation was difficult, mainly because it was hard to find faults in a translation that had hardly any. (SFT1518)

(40) The translation my partner sent to me seemed to be very high quality, so looking for errors was difficult. [...] The exercise we did in the classroom with the web store texts was easier, because of the numerous problems in the translation. (SFT1615)

Some students also found that applying heuristics could benefit 
Suokas, Juho (2020). Testing Usability Methods in Translation Courses: Personas and Heuristic Evaluation. Current Trends in Translation Teaching and Learning E, 7, 4-38.10.51287/cttl_e_2020_2_juho_suokas</doi

their translation processes, but they would prefer this approach without the strict method of evaluation.

(41) In the future, I could use heuristics to help evaluation, but so that the form of the report would be completely free, and that the heuristics would just serve as a list of the points to pay attention to. (SFT1511)

The heuristics were found to have plenty of benefits and drawbacks. Some students preferred them, while others found that they did not suit their translation processes at all. The majority of issues seemed to be related to the specific heuristics. In section 4.4, I will present a few additional issues worth pointing out.

\subsection{Further discussion}

There was some difference between the comments made by the BA-level students and the MA-level students. The MA-level students were more likely to have already developed their own ways of approaching translation, and some said they did not require any more methods to aid in considering the reader/user. Some felt that the methods added unnecessary work to the process (42). One MA-level student also commented that heuristic evaluation would be better suited for translator training than for a more experienced translator (example 43).

(42) Creating specific personas [...] for translating texts seemed to me like 'extra' or somehow unrelated work. [...] In our 
Suokas, Juho (2020). Testing Usability Methods in Translation Courses: Personas and Heuristic Evaluation. Current Trends in Translation Teaching and Learning E, 7, 4-38.10.51287/cttl_e_2020_2_juho_suokas</doi

translator training, we were taught to always consider the function and intended readers of the text. (MTW1511)

(43) Heuristics could be beneficial for those translators who have received a different type of instruction, or beginner translators, who cannot yet see 'the forest for the trees', meaning that they focus too much on specific word choices. The heuristics could be developed more as a teaching tool for early translation courses, where this type of reflection is more necessary than in my case in my fifth year of studies. (MTW1503)

While the MA-level students did not find new work methods as beneficial as students with less translation experience, the UCT methods seemed better suited for BA-level courses for educational purposes. However, for refining and testing new methods in practice, MA-level courses could offer a better, more realistic setting - especially for courses such as MTW in which students work on projects in simulated translation companies.

In a similar study on heuristic evaluation and the UCT heuristics, Tytti Suojanen and Tiina Tuominen (2015) gathered data from students of translation at the University of Tampere and the University of Turku. They used the same heuristics presented in section 3.2. Their data also included material from both BA and MA level courses. Suojanen and Tuominen found that heuristic evaluation was seen as a useful tool once the students had become used to performing the analysis. However, almost half of their students thought the UCT heuristics were challenging or difficult to use. This corresponds with my findings, in that the 
Suokas, Juho (2020). Testing Usability Methods in Translation Courses: Personas and Heuristic Evaluation. Current Trends in Translation Teaching and Learning E, 7, 4-38.10.51287/cttl_e_2020_2_juho_suokas</doi

specific heuristics need refinement. Suojanen and Tuominen suggested a new list of heuristics with modifications according to student feedback, and subsequently, the number of heuristics was reduced from ten to eight (2015: 278-279). Suojanen and Tuominen commented that the new list is not definite and should be tested in various contexts, in concordance with the principles of user-centered design. However, I have not come across many studies of the application of the updated list in practice, yet. Thus, the updated list of heuristics would be a good starting point for future studies on the subject.

\section{CONCLUSIONS}

The aim of this study was to examine student experience of applying two user-centered translation methods in translation courses. The focus on usability and users was seen as positive by the students. Many students commented that they would be interested in using UCT methods more in the future and might even apply them to their own translation processes. The two methods explored in this study had both benefits and drawbacks. Personas seemed to be generally well received by the students. Personas were seen to give a better perspective on the target audience and a new way of justifying individual translation strategies. Many students also enjoyed the process of creating the personas. However, some commented that the process was too time consuming and detracted work from the actual translation process. The heuristic evaluation was praised for its systematic approach. However, the UCT heuristics used herein were also problematic: becoming familiar with the heuristics and 
Suokas, Juho (2020). Testing Usability Methods in Translation Courses: Personas and Heuristic Evaluation. Current Trends in Translation Teaching and Learning E, 7, 4-38.10.51287/cttl_e_2020_2_juho_suokas</doi

performing the evaluation are time-consuming, and the heuristics used were not considered optimal. The data suggests that the heuristics require revision, which could be a starting point for future studies. General heuristics for translation would be a useful tool, while applying heuristic evaluation could be too time-consuming in some projects. For this reason, a welldesigned list of heuristics might be useful as a guideline to follow during the translation process. Usability principles would be most beneficial as an addition to the existing criteria or guidelines and quality principles already in use in the field and translator training.

Based on the findings, I can recommend applying user-centered translation in translation courses. However, at the same time I would be somewhat hesitant to suggest which specific methods to use at this point. The methods used in this study appeared to be most beneficial for students who had some experience with different translation tools and strategies, but who were still in the early-to-mid stages of their translator training. Similarly, while some projects might benefit from applying different usercentered methods, others might not share a similar effect. Thus, when applying UCT methods in translation courses, or in translation overall, I would recommend considering beforehand whether they suit the purpose of the project. UCT methods have good potential for translator training, but the specific methods require refinement. 
Suokas, Juho (2020). Testing Usability Methods in Translation Courses: Personas and Heuristic Evaluation. Current Trends in Translation Teaching and Learning E, 7, 4-38.10.51287/cttl_e_2020_2_juho_suokas</doi

\section{REFERENCES}

\section{Research material}

The research material was gathered between 2015 and 2016 from the University of Eastern Finland and the University of Turku. It consists of 62 documents written by students who used UCT methods during their course work.

\section{Literature}

Byrne, Jody 2012. Scientific and Technical Translation Explained. Manchester: St. Jerome.

Korpio, Marja 2007. "Kaikki sitä tekevät" - vieraalle kielelle kääntäminen Suomen kääntäjien ja tulkkien liiton asiatekstikääntäjien työssä. ["Everyone is doing it" Translating to a foreign language in the work of nonfiction and document translators of The Finnish Association of Translators and Interpreters.] Master's thesis Tampere: University of Tampere

Nielsen, Jakob 1994. "Severity Ratings for Usability Problems" Online article. The Nielsen-Norman Group. Accessed 14.10.2019 at https://www.nngroup.com/articles/howto-rate-the-severity-of-usability-problems/

Nord, Christiane 2013. "Functionalism in translation studies" in Millán, Carmen \& Francesca Bartrina (eds) The 
Suokas, Juho (2020). Testing Usability Methods in Translation Courses: Personas and Heuristic Evaluation. Current Trends in Translation Teaching and Learning E, 7, 4-38. 10.51287/cttl_e_2020_2_juho_suokas</doi

Routledge Handbook of Translation Studies. New York: Routledge. 201-212.

Otava, Anni 2013. Focus on the Audience: Three Cases of Usercentered Translation. Master's thesis. Tampere: University of Tampere.

Purho, Vesa 2000. "Heuristic Inspections for Documentation 10 Recommended Documentation Heuristics" STC Usability SIG Newsletter April 2000, Vol 6, No. 4.

Saldanha, Gabriela \& Shannon O’Brien 2013. Research Methodologies in Translation Studies. London: Routledge.

Suojanen, Tytti; Kaisa Koskinen \& Tiina Tuominen 2015. Usercentered Translation. Oxon: Routledge.

Suojanen, Tytti \& Tiina Tuominen 2015 "Käännösten käytettävyyden heuristinen arviointi" [Heuristic evaluation of the usability of translations.] in Rellstab, D. \& N. Siponkoski (eds) Rajojen dynamiikkaa, Gränsernas dynamik, Borders under Negotiation, Grenzen und ihre Dynamik. VAKKI-symposiumi XXXV. Vaasa: VAKKI Publications 4. 270-280

Suokas, Juho, Kaisa Pukarinen, Stuart von Wolff \& Kaisa Koskinen 2015. "Testing Testing. Putting Translation Usability to the Test." in Trans-Kom 8 (2). 499-519. 
Suokas, Juho (2020). Testing Usability Methods in Translation Courses: Personas and Heuristic Evaluation. Current Trends in Translation Teaching and Learning E, 7, 4-38.10.51287/cttl_e_2020_2_juho_suokas $</$ doi

Accessed 2.3.2020 at http://www.transkom.eu/bd08nr02/transkom_08_02_09_Suokas_ua_Testing.20151211.pdf

Suominen, Selja 2018. Ruokaohjeiden käännösten käytettävyys. Suomennettujen ruokaohjeiden heuristinen arviointi. [Recipe translation usability. Heuristic evaluation of Finnish recipe translations.] Master's thesis. Tampere: University of Tampere.

Tuominen, Tiina; Tytti Suojanen \& Kaisa Koskinen 2015. "Kääntämisen ja käytettävyyden kohtaamisia: käyttäjäkeskeisyys kääntäjän työkaluna" [Encounters of translation and usability: user-centeredness as a translator's tool.] in Aaltonen, Sirkku, Nestori Siponkoski \& Kristiina Abdallah (eds) Käännetyt maailmat [Translated Worlds]. Gaudeamus. 234-250. 